\title{
PENGARUH TELEMEDICINE (WHATSAPP) TERHADAP PENURUNAN KECEMASAN REMAJA HIDUP BERDAMPINGAN DENGAN COVID 19
}

\author{
The Effect of Telemedicine (what's app) On The Reduction of Adolescent anxiety living \\ Combined With Covid 19
}

\author{
Nevy Norma Renityas ${ }^{1}$, Levi Tina Sari ${ }^{2}$ \\ ${ }^{1,2}$ Dosen Program Studi D3 Kebidanan STIKes Patria Husada Blitar
}

Alamat Korespondensi : Program Studi D3 Kebidanan STIKes Patria Husada Blitar Jln.Sudanco Supriyadi No.168 Blitar, Jawa Timur, Indonesia

E-mail : nevy200385@gmail.com

\begin{abstract}
ABSTRAK
Pandemi covid 19 masih berlangsung untuk menekan tingkat kecemasan, maka dilakukan pemberian informasi dan konseling melalui telemedicine (whatsapp) sehingga diharapkan dapat mengurangi kecemasan pada remaja. Desain penelitian menggunakan quasy eksperiment dengan pendekatan pre-post design without control group design. Analisa data untuk mengetahui perbedaan sebelum dan sesudah perlakuan menggunakan uji statistik yaitu paired sample t-test. Hasil penelitian membuktikan bahwa terdapat kenaikan mean antara sebelum dan sesudah sebesar 3,5 poin, dan $\rho$ value $0.0001<\alpha 0.05$ maka terdapat perbedaan sebelum dan sesudah perlakuan. Telemedicine melalui media sosial whatsapp dapat dilakukan kepada remaja baik secara invidu maupun kelompok, melalui whatsapp akan menumbuhkan rasa percaya diri, hal ini karena remaja tidak tatap muka yang membuat mereka merasa tegang dan malu. menurunkan kecemasan pada remaja maka diperlukan konseling melalui media sosial dimana tidak berbatas waktu, dan remaja diharapkan menghindari pemberitaan tentang covid 19 yang terus menerus, serta adanya dukungan keluarga sebagai support sistem dalam pencegahan penularan covid 19
\end{abstract}

Kata kunci : telemedicine (whats app), kecemasan, remaja, covid 19

\section{ABSTRACT}

The COVID-19 pandemic was still ongoing to reduced anxiety levels, so information and counselled are provided through telemedicine (whatsapp) so that it was hoped that it could reduced anxiety in adolescents. The research design used a quasi-experimental approach with a pre-post design approach without control group design. Analysis of the data to determined the difference before and after treatment used a statistical test, namely the paired sample t-test. The results showed that there was an increased in the mean between before and after 3.5 points, and value $0.0001<\alpha 0.05$, so there was a difference before and after treatment. Telemedicine through social media whatsapp could be done to teenagers both individually and in groups, through whatsapp will foster self-confidence, this is because teenagers did not face to face which makes them feel tense and embarrassed. To reduced anxiety in adolescents, counselled was needed through social media where there was no time limit, and adolescents are expected to avoid continuous news about covid 19, as well as family support as a support system in prevented the transmission of covid 19.

Keywords : telemedicine (whats app), anxiety, adolecent, covid 19 


\section{PENDAHULUAN}

Pandemi covid 19 yang dimulai pada Desember 2019, sangat berdampak pada semua kelompok usia mulai dari lansia, remaja dan anak-anak berpotensi terkena penularan covid 19 (Kandeger et al., 2020). Dampak dari penyakit menular khususnya covid 19 pada psikologis yaitu suasana hati yang tertekan, kecemasan, kurang tidur hingga menyebabkan stress (Huang and Zhao, 2021). Dengan adanya gangguan stress pasca trauma akan berdampak pada gangguan depresi jangka panjang (Zhang et al., 2020).

Remaja termasuk pada kelompok penduduk yang khusus, dimana mempunyai kecenderungan emosi yang lebih intens, hal ini dikarenakan lockdown sehingga para remaja ini hanya beraktivitas didalam rumah, yang mana mereka akan mendapat pengawasan dan perhatian dari orang tua, dan remaja merasa sulit melakukan social distancing (Kandeger et al., 2020).

Hasil penelitian pada mahasiswa di Blitar menunjukkan bahwa $58 \%$ remaja menunjukkan sikap negative terhadap pencegahan covid 19 sebelum dilakukan konseling, sehingga menyebabkan kepatuhan dalam melakukan protokol kesehatan berkurang (Noviasari and Sari, 2020), ditambahkan hasil penelitian di Surabaya akibat adanya program stay at home dan sosial distancing pada remaja putri, dimana mereka mengalami kejenuhan dan lelah berada di rumah dan tidak beraktivitas seperti biasa (Puspita, Rozifa and Nadhiroh, 2021).

Kecemasan yang dialami oleh remaja dikarenakan emosi mereka yang masih labil dalam menghadapi kondisi yang tidak terduga dengan tingkat penyebaran covid 19 yang masif (Fitria and Ifdil, 2020). Kecemasan yang dialami oleh remaja seperti ketakutan yang berlebihan jika tertular covid 19 (Aram Jeratallah and Mediantara, 2020). Dikarenakan pandemi covid 19 masih berlangsung untuk menekan tingkat kecemasan, maka dilakukan pemberian informasi dan konseling melalui telemedicine (whatsapp) sehingga diharapkan dapat mengurangi kecemasan pada remaja.

Telemedicine (whatsapp) merupakan salah satu cara untuk melakukan konseling secara pribadi dikarenakan kondisi pandemi covid 19. Menurut penelitian dari (Noviasari and Sari, 2020), bahwa komunikasi melalui media sosial khususnya whatsapp akan meningkatkan pemahaman responden tentang covid 19 dan mempengaruhi sikap positif dalam pencegahan penularan covid 19, sehingga akan berdampak pada efek psikologis responden.

\section{METODE PENELITIAN}

Desain penelitian menggunakan quasy eksperiment dengan pendekatan pre-post design without control group design, yang bertujuan untuk mengetahui perbedaan sebelum dan sesudah perlakuan.

Populasi dalam penelitian ini adalah remaja usia 18-19 tahun di STIKes Patria Husada Blitar, tehnik sampling yang digunakan yaitu purposive sampling dengan kriteria inklusi yaitu bersedia menjadi responden, aktiv menjadi mahasiswa, tidak dalam keadaaan sakit dan menderita covid 19. Sehingga sampel yang memenuhi kriteria inklusi sebesar 25 mahasiswa. 
Instrument yang digunakan dalam penelitian ini terdapat 2 yaitu kuesioner untuk data umum terdiri dari kriteria responden yaitu usia, jenis kelamin, intensitas bertemu dengan teman-teman, anggota keluarga ada menderita covid 19. Kemudian instrument yang kedua yaitu data khusus untuk mengukur tingkat kecemasan dengan menggunakan skala HARS (Hamilton Rating Scale For Anxiety). Kategori skala HARS : $<14$ tidak ada kecemasan; 14-20 kecemasan ringan; 21-27 kecemasan sedang; 28-41 kecemasan berat; 42-56 kecemasan berat sekali. Penelitian dilakukan dimulai bulan Januari-Februari dengan masuk pada group PIK-M 2021.

Analisis data mengunakan distribusi frekuensi pada kriteria responden dan tingkat kecemasan sebelum dan sesudah. Analisa data untuk mengetahui perbedaan sebelum dan sesudah perlakuan menggunakan uji statistik yaitu paired sample t-test.

\section{HASIL DAN PEMBAHASAN \\ Hasil}

1. Data Umum

Tabel 1. Distribusi Frekuensi kriteria responden $(n=25)$

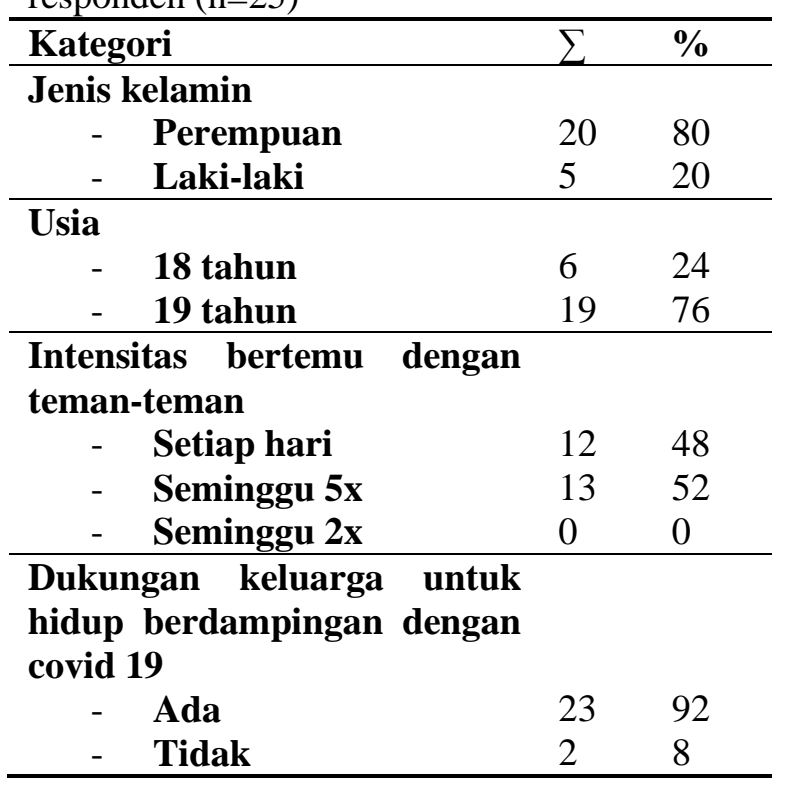

\begin{abstract}
Aktivitas olah raga
- Setiap hari

- Seminggu 2x

520

- Seminggu 1x

$5 \quad 20$

$15 \quad 60$

Dari data diatas dapat disimpulkan bahwa jumlah perempuan sebesar $80 \%, 76 \%$ berusia 19 tahun, 52\% responden bertemu dengan teman-temannya seminggu $5 x$, dan $92 \%$ responden mempunyai dukungan keluarga untuk hidup berdampingan dengan covid 19, $60 \%$ responden melakukan aktivitas olahraga seminggu $1 \mathrm{x}$.
\end{abstract}

\section{Data Khusus}

Tabel 2. Distribusi Frekuensi kecemasan sebelum dan sesudah perlakuan

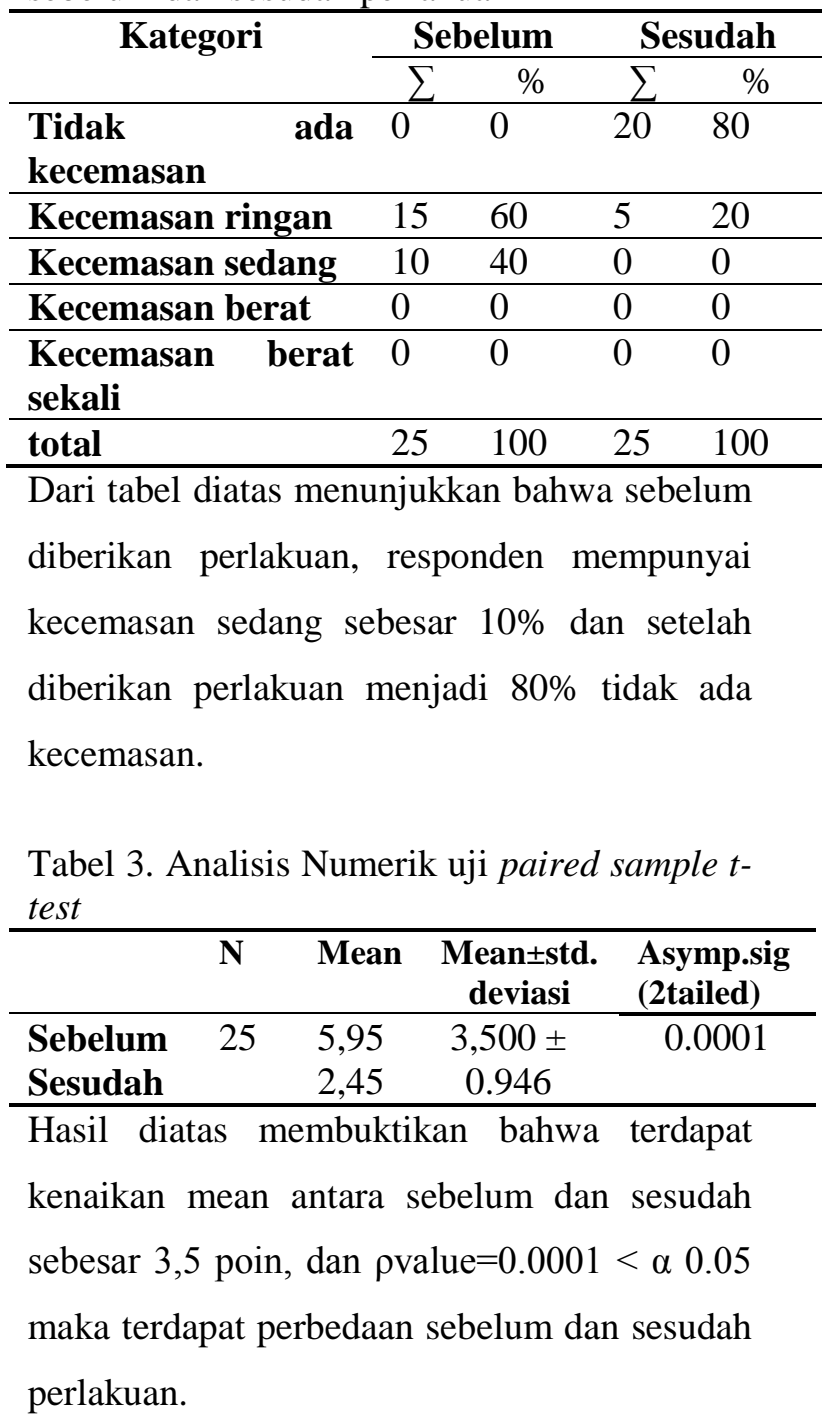




\section{Pembahasan}

\section{Kecemasan Sebelum dilakukan perlakuan}

Child Mind Institute Amarika Serikat mengatakan bahwa 32,9\% anak-anak dan remaja diseluruh dunia mengalami gangguan kecemasan. Gangguan kecemasan yang terjadi pada remaja yaitu kesulitan belajar, gangguan makan, hingga kesulitan untuk bersosialisasi(Yusfarani, 2021).

Hasil penelitian membuktikan bahwa $40 \%$ responden mengalami kecemasan dengan katagori sedang. Hal ini dikarenakan remaja takut jika tertular covid 19, karena pembelajaran mulai aktiv tatap muka dan kurangnya informasi yang didapat tentang cara hidup berdampingan dengan covid 19. Hal ini sejalan dengan penelitian dari Fitria dan Ifdil bahwa beberapa faktor yang menyebabkan kecemasan pada masa pandemic covid 19 yaitu kurang informasi dan terlalu heboh di media massa maupun media sosial (Fitria and Ifdil, 2020).

Jenis kelamin perempuan juga menjadi salah satu faktor seseorang mengalami kecemasan. Pada penelitian ini jenis kelamin perempuan sebesar $80 \%$. Hal ini sejalan dengan penelitian di Wuhan China bahwa perempuan lebih mengalami gangguan kecemasan lebih tinggi daripada laki-laki (Xiao et al., 2020). Namun penelitian Changzi medical college di Cina mengatakan bahwa tidak ada perbedaan signifikan antara jenis kelamin dengan kecemasa, karena baik lakilaki maupun perempuan mengalami stres dan emosi negative yang sama akibat pandemi covid 19 (Wenjun et al., 2020). Penelitian pada mahasiswa di medical college Rawalpindi
Pakistan bahwa depresi dan kecemasan sehingga menyebabkan tekanan psikologi ditemukan pada gender perempuan (Azad et al., 2017)

Perempuan mempunyai ketidakstabilan emosi sehingga menyebabkan kecemasan yang berlebihan terhadap pandemi covid 19, hal ini disebabkan karena fluktuasi hormon estrogen yang menyebabkan perubahan mood atau emosi (Puspitasari and Aprillia, 2007).

Intensitas pertemuan yang sering dengan teman-teman dapat menyebabkan kecemasan, namun juga dapat menurunkan kecemasan karena remaja dapat berbagi pengalaman. Hasil penelitian menyebutkan bahwa semingggu $5 \mathrm{x}$ mereka bertemu dengan teman di tempat kuliah. Kegiatan sosial mapaun kuliah secara tatap muka maka akan menyebabkan kecemasan tertular covid 19 (Jarnawi, 2020)

\section{Kecemasan Sesudah dilakukan perlakuan}

Hasil penelitian mengatakan bahwa $80 \%$ tidak mengalami kecemasan. Hal ini dikarenakan waktu perlakuan selama 6 minggu dan setiap hari memberikan informasi serta konseling secara umum di group whats app, konseling dilakukan tidak berbatas waktu sehingga peserta dengan bebas mengeluarkan pendapat dan perasaannya tentang hidup berdampingan dengan covid 19 .

Pengetahuan responden berhubungan dengan tingkat kecemasan, pengetahuan yang positif akan menurunkan tingkat kecemasan (Germani et al., 2020). Responden pun masih mahasiswa aktiv di sekolah tinggi kesehatan sehingga mereka lebih mudah memahami dan 
menerima masukan sehingga dapat mempermudah proses konseling. Namun, pengetahuan yang di dapat dari media sosial yang berlebihan akan menyebabkan kecemasan yang tinggi (Jungmann and Witthöft, 2020). Karena informasi yang berlebihan akan membuat seseorang menjadi khawatir sehingga merasakan kecemasan terhadap penularan covid 19 .

Oleh karena itu, saat proses konseling dimana responden tidak melihat media sosial terkait pemberitaan covid 19, sehingga dapat menurunkan tingkat kecemasan. Hal ini sesuai dengan penelitian di jepang bahwa kecemasan menurun terhadap penularan covid 19 di masa pandemi disebabkan karena faktor pembatasan media sosial dan meningkatkan coping agama (Shiina et al., 2020).

Dukungan keluarga dalam pencegahan covid 19 dan hidup berdampingan dengan covid 19 sangat berpengaruh terhadap penurunan kecemasan. Hal ini diperkuat oleh penelitian dengan metode sistematik review mengatakan bahwa dukungan keluarga dan sosial masyarakat yang kuat akan dapat mengurangi tingkat kecemasan pada masa pandemi, dan merupakan strategi koping yang positif sebagai pencegahan kecemasan atau stres (Carmassi et al., 2020). Oleh karena itu, support sistem dalam keluarga sangat penting untuk penurunan kecemasan.

\section{Pengaruh telemedicine (whatsapp) \\ terhadap kecemasan}

Remaja pada era milenial lebih suka menggunakan media sosial sebagai alat komunikasi, dan salah satu media sosial yang sering digunakan untuk alat komunikasi adalah whatsapp (Sari, 2019). Oleh karena itu, konseling melalui whats app lebih efektif karena tidak berbatas waktu, cepat, tidak merasa ragu dalam mengeluarkan pendapat dan menyampikan permasalahan (sugiarti, 2020).

Hasil penelitian menunjukkan bahwa $\rho$ value $=0.0001<\alpha 0.05$ maka terdapat perbedaan sebelum dan sesudah perlakuan. Maka, telemedicine dengan menggunakan whatsapp lebih efektif untuk penurunan kecemasan. Hal ini diperkuat oleh penelitian di remaja Kelas XII MA Wanadadi Banjarnegara mengatakan bahwa layanan whatsapp lebih efektif dalam mereduksi tingkat kecemasan terhadap bahaya covid 19 (Fadliansyah and Humaera, 2021).

Telemedicine melalui media sosial whatsapp dapat dilakukan kepada remaja baik secara invidu maupun kelompok, melalui whatsapp akan menumbuhkan rasa percaya diri (Sugiarti, 2020). Hal ini karena remaja tidak tatap muka yang membuat mereka merasa tegang dan malu.

Selain konseling dengan telemedicine, salah satu faktor pendukung penurunan kecemasan yaitu dengan aktivitas olah raga. Hasil penelitian menyatakan bahwa $60 \%$ responden melakukan aktivitas olah raga seminggi sekali dan $20 \%$ melakukan olah raga setiap hari. Hal ini sependapat dengan penelitian di Hainan Cina membuktikan bahwa latihan otot progresiv dapat meningkatkan kualitas tidur sehingga akan mengurangi kecemasan terhadap covid 19 (Liu et al., 2020). Olahraga juga menjadi pilihan untuk 
meningkatkan daya tahan tubuh. Olahraga atau aktivitas fisik bermanfaat meningkatkan daya tahan tubuh, meningkatkan kebugaran, mengurangi stress, meningkatkan rasa percaya diri (Ulfa and Mikdar, 2020).

\section{PENUTUP}

Terdapat perbedaan sebelum dan sesudah perlakuan dengan menggunakan telemedine melalui whatsapp terhadap penurunan kecemasan hidup berdampingan dengan covid 19. Pada masa pandemi covid 19 yang tidak tahu kapan berakhirnya akan mengharuskan hidup berdampingan dengan covid 19, untuk menurunkan kecemasan pada remaja maka diperlukan konseling melalui media sosial dimana tidak berbatas waktu, dan remaja diharapkan menghindari pemberitaan tentang covid 19 yang terus menerus, serta adanya dukungan keluarga sebagai support sistem dalam pencegahan penularan covid 19.

\section{DAFTAR PUSTAKA}

Aram Jeratallah, D. and Mediantara, Y. (2020) 'Covid-19 dan Perubahan Komunikasi Sosial', Persepsi: Communication Journal, 3(1), pp. 94-102. doi: 10.30596/persepsi.v3i1.4510.

Azad, N. et al. (2017) 'Anxiety And Depression In Medical Students Of A Private Medical College', Journal of Ayub Medical College, Abbottabad: JAMC, 29(1), pp. 123-127.

Carmassi, C. et al. (2020) 'PTSD symptoms in healthcare workers facing the three coronavirus outbreaks: What can we expect after the COVID-19 pandemic', Psychiatry Research, 292(January). doi: 10.1016/j.psychres.2020.113312.

Fadliansyah, A. and Humaera, S. (2021) 'EFEKTIVITAS

LAYANAN INFORMASI MENGGUNAKAN MEDIA WHATSAPP UNTUK
MEREDUKSI ANXIETYTERHADAP BAHAYA COVID-19', Jurnal Talenta Psikologi, 16(1), pp. 19-25. Available at:

http://www.jurnal.usahidsolo.ac.id/index .php/JTL/issue/view/97.

Fitria, L. and Ifdil, I. (2020) 'Kecemasan remaja pada masa pandemi Covid -19', Jurnal EDUCATIO: Jurnal Pendidikan Indonesia, 6(1), p. $1 . \quad$ doi: $10.29210 / 120202592$.

Germani, A. et al. (2020) 'Emerging adults and covid-19: The role of individualismcollectivism on perceived risks and psychological maladjustment', International Journal of Environmental Research and Public Health, 17(10). doi: 10.3390/ijerph17103497.

Huang, Y. and Zhao, N. (2021) 'Corrigendum to Generalized anxiety disorder, depressive symptoms and sleep quality during COVID-19 outbreak in China: a web-based cross-sectional survey [Psychiatry Research, 288 (2020) 112954]', Psychiatry Research, 299(April), p. 113803. doi: 10.1016/j.psychres.2021.113803.

Jarnawi, J. (2020) 'Mengelola Cemas Di Tengah Pandemik Corona', At-Taujih: Bimbingan dan Konseling Islam, 3(1), p. 60. doi: 10.22373/taujih.v3i1.7216.

Jungmann, S. M. and Witthöft, M. (2020) 'Since January 2020 Elsevier has created a COVID-19 resource centre with free information in English and Mandarin on the novel coronavirus COVID- 19 . The COVID-19 resource centre is hosted on Elsevier Connect, the company', $s$ public news and information ', (January).

Kandeger, A. et al. (2020) 'Major depressive disorder comorbid severe hydrocephalus caused by Arnold - Chiari malformation Does exposure to a seclusion and restraint event during clerkship influence medical student's attitudes toward psychiatry?', Indian Journal of Psychiatry, 59(4), pp. 2017-2018. doi: 10.4103/psychiatry.IndianJPsychiatry.

Liu, K. et al. (2020) 'Effects of progressive muscle relaxation on anxiety and sleep quality in patients with COVID-19', Complimentary therapies in Clinical Practice, 39(may). doi: doi: 10.1016/j.ctcp.2020.101132. 
Noviasari, I. and Sari, L. T. (2020) 'The Effectiveness of In-Network Methods (Whatsapp Group) to the Attitudes of Covid 19 Prevention of D3 Midwifery Students STIKes Patria Husada Blitar', Jurnal Ners dan Kebidanan (Journal of Ners and Midwifery), 7(3), pp. 410-414. doi: 10.26699/jnk.v7i3.art.p410-414.

Puspita, I. M., Rozifa, A. W. and Nadhiroh, A. M. (2021) 'Gambaran Kecemasan Dan Kepatuhan Remaja Putri Terhadap Kebiasaan Baru Di Masa Pandemi Covid-19', JOMIS (Journal of Midwifery Science), 5(1), pp. 52-61. doi: 10.36341/jomis.v5i1.1492.

Puspitasari, N. and Aprillia, N. (2007) 'Faktor yang Mempengaruhi Tingkat Kecemasan pada Wanita Perimenopause', Indonesian Journal of Public Health, 4(1).

Sari, L. T. (2019) 'Perbedaan Penggunaan Facebook dan Instagram terhadap Perilaku Seks Bebas Remaja Usia 15-17 Tahun', Jurnal Ners Dan Kebidanan, 6(1), pp. 93-100. doi: 10.26699/jnk.v6i1.ART.p093.

Shiina, A. et al. (2020) 'Relationship between perception and anxiety about COVID-19 infection and risk behaviors for spreading infection: A national survey in Japan', 6(January). Available at: https://www.ncbi.nlm.nih.gov/pmc/articl es/PMC7331545/pdf/main.pdf.

sugiarti, Y. (2020) 'Penerapan E-Konseling Berbasis Whatsapp dalam Meningkatkan Kepercayaan Diri pada Peserta Didik SMK Negeri 5 Banjarmasin', Jurnal Sipatokkong BPSDM Sulawesi Selatan, 1(2), pp. 137-142. Available at: https://ojs.bpsdmsulsel.id/.

Ulfa, Z. D. and Mikdar, U. Z. (2020) 'Dampak Pandemi Covid-19 terhadap Perilaku Belajar, Sosial dan Kesehatan bagi Mahasiswa FKIP Universitas Palangka Raya', JOSSAE: Journal of Sport Science and Education, 5(2), p. 124. doi: 10.26740/jossae.v5n2.p124-138.

Wenjun, C. et al. (2020) 'The psychological impact of the COVID-19 epidemic on college students in China', Psychiatry Research, 287(March 20, 2020), pp. 15. Available at: http://www.embase.com/search/results?s ubaction=viewrecord\&from=export\&id
=L2005406993\%0Ahttp://dx.doi.org/10. 1016/j.psychres.2020.112934.

Xiao, H. et al. (2020) 'Social distancing among medical students during the 2019 coronavirus disease pandemic in china: Disease awareness, anxiety disorder, depression, and behavioral activities', International Journal of Environmental Research and Public Health, 17(14), pp. 1-13. doi: 10.3390/ijerph17145047.

Yusfarani, D. (2021) 'Hubungan Kecemasan dengan Kecendrungan Psikosomatis Remaja Pada Pandemi Covid 19 Di Kota Palembang', Jurnal Ilmiah Universitas Batanghari Jambi, 21(1), p. 295. doi: 10.33087/jiubj.v21i1.1328.

Zhang, C. et al. (2020) 'The Psychological Impact of the COVID-19 Pandemic on Teenagers in China', Journal of Adolescent Health, 67(6), pp. 747-755. doi: 10.1016/j.jadohealth.2020.08.026. 